\title{
Morphology of Van der Waals surfaces and magnetic hysteresis in cobalt intercalated InTe
}

\author{
V.B.Boledzyuk ${ }^{1}$, Z.D.Kovalyuk ${ }^{1}$, Z.R.Kudrynskyi ${ }^{1}$, \\ A.D.Shevchenko ${ }^{2}$
}

\author{
${ }^{1}$ I.Frantsevich Institute of Materials Science Problems (Chernivtsi \\ Branch), National Academy of Sciences of Ukraine, \\ 5 I.Vilde Str., 58001 Chernivtsi, Ukraine \\ ${ }^{2}$ G.Kurdyumov Institute for Metal Physics, \\ National Academy of Sciences of Ukraine, \\ 36 Akad. Vernadskogo Ave., 03680 Kyiv, Ukraine
}

Received March 31, 2015

\begin{abstract}
The influence of $\mathrm{Co}^{2+}$ intercalation on the properties of InTe monocrystals was investigated. The intercalation of cobalt in InTe are not leading to change of the crystal lattice parameters, leaving the same structural type of the samples. It is established that in investigated intercalates on the Van der Waals surfaces of InTe layers there is formation clusters impurity, which consist from cobalt nanoparticles of the pyramidal form. Cobalt intercalated InTe possesses ferromagnetic properties: the dependence of its magnetic moment from magnetic field has the form of hysteresis loop that is characteristic for ferromagnets.
\end{abstract}

Keywords: intercalation, InTe, magnetic-field gradient, 3d-metals, hysteresis

Исследовано влияние интеркалирования ионов $\mathrm{Co}^{2+}$ на свойства монокристаллов InTe. Внедрение кобальта в InTe не приводит к изменениям кристаллографических параметров кристаллов, оставляя неизменным структурный тип исследуемых образцов. Установлено, что в исследуемых интеркалатах на ван-дер-ваальсовских плоскостях межслоевого пространства происходит формирование кластеров примеси, которые состоят из наночастиц кобальта пирамидальной формы. В кобальтовых интеркалатах InTe обнаружено проявление ферромагнетизма: зависимость магнитного момента от напряженности магнитного поля имеет вид петель гистерезиса, характерных для ферромагнетиков.

Морфологія ван-дер-ваальсівських поверхонь та магнітний гістерезис кобальтових інтеркалатів InTe. В.Б.Боледзюк, З.Д.Ковалюк, З.Р.Кудринський, А.Д.ІШевченко.

Досліджено вплив інтеркалювання іонів $\mathrm{Co}^{2+}$ на властивості монокристалів InTe. Впровадження кобальту в InTe не призводить до зміни кристалографічних параметрів кристалів, залишаючи тим самим незмінним структурний тип досліджуваних зразків. Встановлено, що у досліджуваних інтеркалатах на ван-дер-ваальсівських поверхнях міжшарового простору відбувається формування кластерів домішки, які складаються із наночасток кобальту пірамідальної форми. У кобальтових інтеркалатах InTe встановлено прояв феромагнетизму: залежність магнітного моменту від напруженості магнітного поля має вигляд гістерезисних петель, характерних для феромагнетиків. 


\section{Introduction}

Modern materials science needs the development of methods for controlled synthesis of binary semiconductor compounds with required composition, structure and, as a result, predetermined electrical parameters. Layered compounds $A^{3} B^{6}(A=\ln , G a ; B=S e, T e)$ find a use for semiconductor engineering as detectors of IR and high-energy radiation, piezoelectric sensors, solid-state accumulators of hydrogen, etc. [1-4]. Such compounds, when subjected to intercalation, are able to absorb and localize in their interlayer spaces atoms and ions of various elements [5,6] keeping the initial lattice structure. Investigation of layered semiconductors intercalated with magnetic elements from the iron group ( $\mathrm{Fe}, \mathrm{Co}$, and $\mathrm{Ni}$ ) is a matter of the topical interest. Obtained intercalates combine in themselves both the semiconductor properties inherent to the initial compounds and the magnetic properties of intercalated impurities.

Investigations of InTe single crystals are preferably concentrated on studies of the structure $[7,8]$ and electrical properties [9, 10]. At present there are no data about investigation of intercalates based on indium telluride.

\section{Experimental}

Similarly to TISe crystals, indium monotelluride InTe crystallizes into a lattice structure with the space group $14 / \mathrm{mcm}$ [11]. Among layered $A^{3} B^{6}$ compounds, it is distinguished by more complex lattice structure in comparison to other $A^{3} B^{6}$ compounds. In its lattice $\mathrm{In}^{3+}$ ions are tetrahedral coordinated with respect to $\mathrm{Te}^{2+}$ ions forming $\operatorname{lnTe}_{4 / 2}$ chains. At the same time $\mathrm{In}^{+}$ ions form the eightfold tetragonal antiprismatic coordination with respect to $\mathrm{Te}^{2-}$ ions. Different in charge $\operatorname{~In~}^{3+}$ and $\mathrm{In}^{+}$ions occupy two different crystallographic positions (Fig. 1) and prevent free transfer of electrons from $\mathrm{In}^{+}$to $\mathrm{In}^{3+}$ ions. It is known [11] that indium monotelluride crystallizes at the temperature of $969 \mathrm{~K}$ in structure belonging to the tetragonal syngony, which at increasing temperature and pressure transforms into the cubic one of $\mathrm{NaCl}$ type. InTe single crystals were grown by the Bridgman method from stoichiometric melt. The stoichiometry of the obtained crystals, their homogeneity and phase composition have been analyzed by X-ray methods. The lattice parameters of the grown crystals are $a=8.455$ and $c=7.136 \AA$ (space group

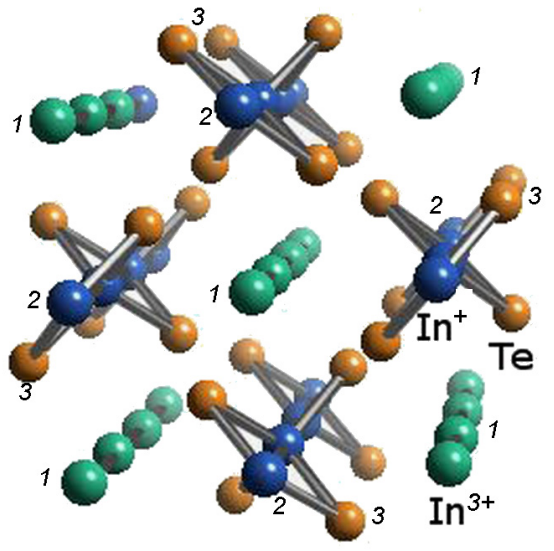

Fig. 1. Crystal structure of $\ln T e . \ln ^{3+}$ and $\operatorname{In}^{+}$ ions in two different crystallographic positions are in green (1) and blue (2) colors, respectively. Te atoms are shown in yellow (3) color.

$I 4 / \mathrm{mcm}$ ) and agree to the literature data [12]. In our experiments we used samples with dimensions of $5 \times 5 \times 1 \mathrm{~mm}^{3}$.

The intercalation of $\mathrm{Co}^{2+}$ ions into the interlayer spaces of the InTe samples was carried out by applying electrochemical method under galvanostatic conditions. The details for the intercalation of $3 d$ transition metals into layered $A^{3} B^{6}$ semiconductors are described in $[13,14]$. The structure of obtained intercalate $\mathrm{Co}_{x} \operatorname{InTe}(x=0.1)$ was investigated by an $e x$ situ method of atomicforce microscopy (AFM) by means of Nanoscope IIIa Dimension 300SPM microscope in tapping mode. The radius of a probe spike was not more than $10 \mathrm{~nm}$. The magnetization of $\mathrm{Co}_{x} \mathrm{InTe}$ intercalates was measured by using Vibrating Magnetometer 7404 VSM in magnetic fields with a strength up to 3000 Oe.

\section{Results and discussion}

Carried out X-ray analysis of the obtained $\mathrm{CO}_{0.1}$ InTe intercalates showed that the lattice structure and its parameters remained unchanged after the intercalation. This fact is typical for layered $A^{3} B^{6}$ semiconductors and titanium dichalcogenides $\mathrm{TiX}_{2}(\mathrm{X}=\mathrm{S}$, Se, Te) intercalated with the magnetic impurities [15-17]. Such behavior of the lattice parameters is explained as a result of competition between hybridization of the $3 d$ orbitals of Co atoms with $p$-states of Te atoms (formation of "constricting" Te-Co-Te bondings) and repulsion of the Te atoms.

Layered InTe crystals because of their structure are characterized by higher den- 


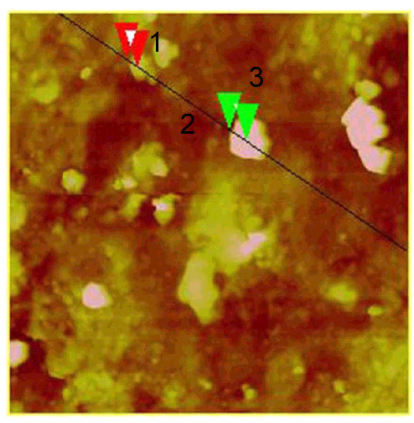

a)

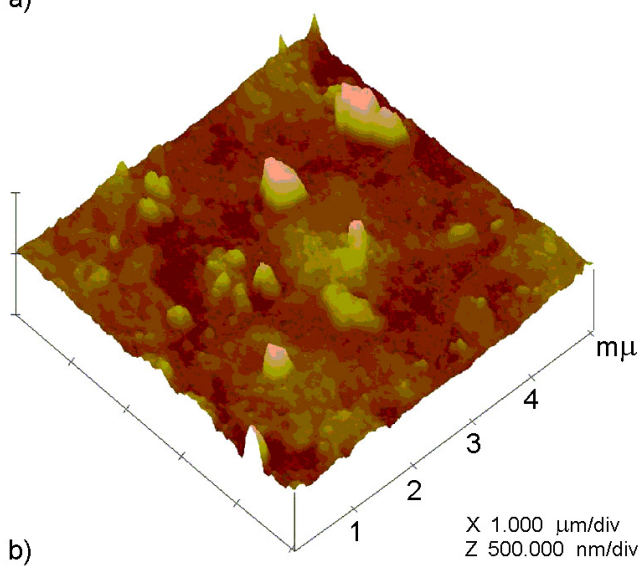

sity of defects at Van der Waals planes in the interlayer space as compared to other layered compounds, in particular InSe and GaSe. During electrochemical intercalation there is a possibility for atoms or molecules of the intercalant to be adsorbed at such surfaces and appearance of the impurity's islands is also possible. Because of such extended defects the creation of intercalant nanostructures is possible which, by turn, will affect properties of the initial crystals. Fig. 2 shows an AFM pattern of the inner surfaces of the $\mathrm{CO}_{0.1}$ InTe intercalates. These compounds were obtained by electrochemical intercalation in the constant magnetic field of $4 \mathrm{kOe}$. In this pattern one can see high amount of small nanoformations 10-20 nm high, which are aggregated into clusters with lateral dimensions of 1-2 $\mu \mathrm{m}$. Besides, there are single nanoformations of pyramidal form, too (Fig. 2b). Their height is preferably 50 to $100 \mathrm{~nm}$ though there are separate nanoformations with height above $100 \mathrm{~nm}$. As a reason for the appearance of such different nanoformations one can consider the quality of the Van der Waals surfaces of the layered crystal. Probably the intercalant aggregates appear at those places of the Van der Waals planes where defects are localized whereas the separate nanoformations arise in the nanocavities on
Fig. 2. 2D (a) and 3D (b) AFM patterns of the Van der Waals surface of $\mathrm{Co}_{0.15}$ InTe intercalated in magnetic field: 1 - Co cluster, 2 nanocavity, 3 - separate nanoformation of Co. the layer surfaces. In our opinion, the nucleation and formation of Co clusters occurs because of self-organization of the intercalant atoms. The exchange magnetic interaction between the Co atoms is the determinant in this process. The presence of an external magnetic field in the intercalation process should also be taken into account as this field promotes the formation of both cobalt clusters and its pyramidal nanoformations.

As follows from our previous studies [13-15], intercalation of the layered semiconductors with magnetic elements in the constant magnetic field varies properties of the initial samples. After such intercalation in paramagnetic layered crystals, one can observe so-called "ferromagnetic response" - intercalated samples demonstrate ferromagnetic properties. They consist in the appearance of hysteresis characteristics for magnetization that is typical for ferromagnetic materials. Fig. 3 shows dependences of specific magnetic moment $m$ on magnetic field strength for $\mathrm{Co}_{x} \mathrm{InTe}$ intercalates with the different concentrations of inserted cobalt $(x=0.1$ and 0.15$)$. At once, it is worth to note that similar properties have not been observed for $\mathrm{Co}_{x}$ InTe intercalates obtained without applying magnetic field. This fact means that magnetic field deci- 

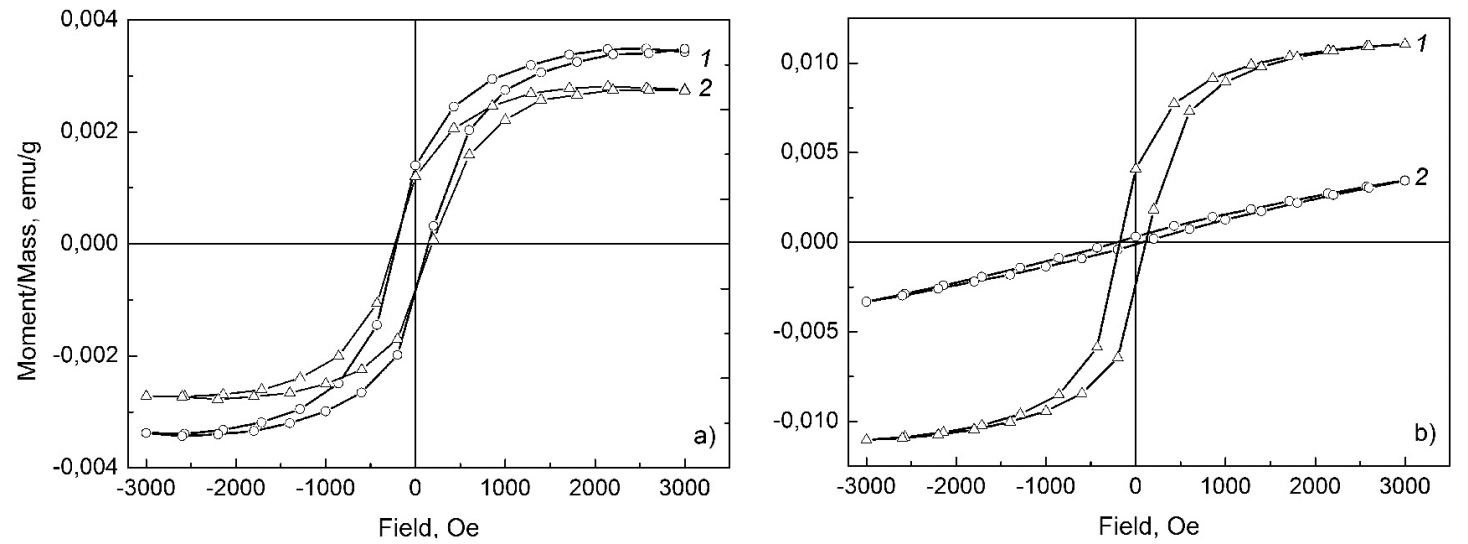

Fig. 3. Dependences of specific magnetic moment on magnetic field strength for $\mathrm{Co}_{0.1} \operatorname{lnTe}(\mathrm{a})$ and $\mathrm{Co}_{0.15}$ InTe (b) insertion compounds intercalated in magnetic field. Orientation of the magnetic field: 1 - along the layers and 2 - across to them.

sively effects on the formation and properties of the $3 d$ transition metal intercalates based on the layered semiconductors.

Strong anisotropy of the structure and electrical characteristics, in the directions along and across the layers, is inherent to the layered crystals. As one can see from the represented $m=f(\mathbf{H})$ dependences, these curves for both the samples depend on magnetic field orientation with respect to the layers and concentration of the inserted cobalt. The values of the coercive force $\mathbf{H}_{C}$ established from Fig. 3 are 205.66 and $177.57 \mathrm{G}$ for $\mathrm{Co}_{0.1} \mathrm{InTe}$ and 144.13 and $145.26 \mathrm{G}$ for $\mathrm{Co}_{0.15} \operatorname{lnTe}$ at the directions of $\mathbf{H}$ along and across the layers, respectively, what is typical for hard-magnetic ferromagnets. The values of the specific saturated magnetic moment $m_{S}$ in $\mathbf{H} \| \mathbf{c}$ configuration for the $\mathrm{CO}_{0.1} \operatorname{lnTe}$ and $\mathrm{CO}_{0.15}$ InTe samples differ slightly $-3.45 \cdot 10^{-3}$ and $3.396 \cdot 10^{-3} \mathrm{emu} / \mathrm{g}$, respectively, in comparison to the values of $m_{S}$ in He configuration, which are equal to $2.79 \cdot 10^{-3}$ and $11.04 \cdot 10^{-3} \mathrm{emu} / \mathrm{g}$, respectively. The view of the hysteresis loops in $m=f(\mathbf{H})$ dependences with the magnetic field directed along the layers indicates on ferromagnetic interaction between the Co atoms. As regards the $m=f(\mathbf{H})$ dependences when the field is across the layers, in this case their form is typical for ferromagnetic interaction between the layers of the intercalant.

The difference in the $m=f(\mathbf{H})$ dependences measured at the two different magnetic field directions for the $\mathrm{Co}_{x} \mathrm{InTe}$ intercalates can be explained taking into account the crystal structure of the layered $A^{3} B^{6}$ compounds and shown above the AFM pattern. Being intercalated into the layered crystals the intercalant becomes localized in the Van der Waals gaps between adjacent planes of the chalcogen atoms whereas the structure of separate B-A-A-B covalent layers remains unchanged. In dependence on concentration of the intercalated cobalt that results in size and amount of the created clusters, there is possibility for interaction of the clusters between themselves in a layer plane as well as the exchange interaction between the intercalant layers through Se atoms. About the existence of similar interaction through chalcogen atoms for layered compounds $\mathrm{MnA}^{3} \mathrm{~B}^{6}$ it was reported, for instance, in [18]. As it is seen from the $m=f(\mathbf{H})$ dependence at the magnetic field directed across the layers (curves 1 in Figs. $3 \mathrm{a}, \mathrm{b}$ ), for the $\mathrm{Co}_{0.1} \operatorname{InTe}$ and $\mathrm{Co}_{0.15} \mathrm{InTe}$ samples the specific magnetic moment values are practically the same. When the magnetic field is directed along the layers, the value of the specific magnetic moment for $\mathrm{CO}_{0.15} \mathrm{InTe}$ is higher as compared to that for $\mathrm{Co}_{0.1}$ InTe. It indicates on increased interaction of the clusters in the layers' plane because of the higher concentration of intercalated cobalt.

When external magnetic field is applied, magnetic charges appear in the Co clusters created during the intercalation. Their appearance induces demagnetizing field directed against the real magnetic field in the ferromagnetic cluster. This field is characterized by demagnetizing factor the value of which depends on the direction of the external magnetic field. According to [19], distance between the magnetic charges is the 
higher the less the demagnetizing factor is and thus its counteraction to the real magnetic field is smaller. In our case, when the external magnetic field is directed across the layers, the demagnetizing field will be stronger affect the $m=f(\mathbf{H})$ dependence as the interaction between the Co clusters is restricted by the covalent layers of the initial InTe crystal. In our opinion just this factor is the main reason for the difference in the $m=f(\mathbf{H})$ behavior at the two different magnetic field directions for the $\mathrm{Co}_{x} \mathrm{InTe}$ intercalates.

\section{Conclusions}

Applying the constant magnetic field at electrochemical intercalation of layered InTe crystals with $\mathrm{Co}^{2+}$ ions leads to formation of the nanodimensional inclusions (clusters) on the Van der Waals surfaces in the interlayer gaps. This results in the variation of magnetic properties of the $\mathrm{Co}_{x} \mathrm{InTe}$ intercalates $(x=0.1$ and 0.15$)$ in comparison to the initial samples. At the room temperature the obtained $\mathrm{Co}_{x} \mathrm{InTe}$ compounds have magnetic properties typical for ferromagnetic materials - the dependences of the specific magnetic moment on magnetic field strength have the form of hysteresis loops.

\section{References}

1. V.G.Dmitriev, G.G.Gurzadyhan, D.N.Nikogosyan, Handbook of Nonlinear Optical Crystals, Springer, Berlin (1997).

2. C.Kubler, R.Huber, S.Tubel et al., App.Phys. Lett., 85, 3360 (2004).
3. G.V.Lashkarev, A.I.Dmitriev, M.V.Radchenko et al., in: Proc. 6th Conf. on Nuclear and Particle Physics, Luxor, Egypt (2007).

4. Yu.I.Zhirko, Z.D.Kovalyuk, M.M.Pyrlja et al., in: Hydrogen Materials Science and Chemistry of Carbon Nanomaterials, ed. T.N.Veziroglu, Springer (2007).

5. F.A.Levy (ed.), Intercalated Layered Materials, Reidel, Dordrecht (1979).

6. R.Shollhorn, Physica B, 99B, 89 (1980).

7. J.H.C.Hogg, H.H.Sutherland, Acta Cryst., B32, 2689 (1976).

8. T.Chattopadhyay, R.P.Santandrea, H.G.Von Schering, Phys. Chem. Solids, 46, 351 (1985).

9. M.M.Nassary, S.A.Hussein, A.E.Belal et al., Phys.Stat.Sol. (A), 145, 151 (1994).

10. V.V.Shchennikov, K.V.Savchenko, S.Popova, Phys. Solid State, 42, 1036 (2000).

11. D.M.Chyzhykov, V.P.Shchastlyvyi, Tellurium and Tellurides, Nauka, Moscow (1966).

12. Landolt-Bornstein Numerical Data and Functional Relationships in Science and Technology, ed. by O.Madelung, Springer-Verlag, Berlin (1982).

13. A.P.Bakhtinov, V.B.Boledzyuk, Z.D.Kovalyuk et al., Phys. Solid State, 55, 1148 (2013).

14. V.B.Boledzyuk, Z.D.Kovalyuk, M.N.Pyrlya et al., Inorgan. Mater., 50, 976 (2014).

15. Z.D.Kovalyuk, V.B.Boledzyuk, V.V.Shevchyk et al., Semiconductors, 46, 971 (2012).

16. A.N.Titov, A.V.Kuranov, V.G.Pleschev et al., Phys. Rev. B, 63, 035106-1 (2001).

17. V.G.Pleshchev, A.N.Titov, S.G.Titova, Phys. Solid State, 45, 433 (2003).

18. V.Lashkarev, V.V.Slynko, Z.D.Kovalyuk et al., Mater. Sci. and Engin. C, 27, 1052 (2007).

19. S.Tikadzumi, Fizika ferromagnetizma: Magnitnye svojstva veshchestva, Mir, Moscow (1983). 